\title{
Socialising Animal Disease Risk: inventing Traceback and re- inventing animals
}

\author{
ANDREW DONALDSON ${ }^{1}$
}

\begin{abstract}
Through a discussion of how the inventive practices of farm animal genomics interact with animal disease and food risk, this paper aims to expand our notion of what constitute the social dimensions of animal genomics, and why attention to animals and the contemporary issues surrounding them can offer us insights into genomics in general. Through a case study of the circumstances surrounding the invention of the DNA TraceBack technology in the midst of the BSE crisis, I argue that, rather than just examining genomics in and of itself, we should follow the inventions of genomics and their inseparable informational material environments. Then we can see the need for a social science approach that is more attentive to the inseparability of politics and science at the material level and can invent new, more inclusive, problems and research questions.
\end{abstract}

\section{Contemporary connections}

First, a confession: although I study agriculture, farm animal genomics ${ }^{2}$ does not form a central empirical focus of my research. But in April 2001, when an epidemic of foot and mouth disease (FMD) was raging through farmed cattle, sheep and pigs in the UK, the field did come into contact with my own. That month, the BBC documentary series, Panorama, screened a polemic that focussed less on the impacts of FMD and more on the modern history and contemporary situation of British agriculture. With the cost of handling FMD to be a further drain on the public purse, ${ }^{3}$ the documentary set out to question whether farming served the public interest well enough to justify its continued public subsidy. If left to trade un-supported in a liberalised global market, British farming would surely have to change in order to remain competitive. We were shown precursors to an evermore technologically intensive agribusiness, culminating in a brief interview with Graham Bulfield, then director of the Roslin Institute. He outlined the importance of genomics-based innovations in animal breeding to increase production efficiency and resistance to disease. ${ }^{4}$ In that moment several of the objects of my research - animals and their diseases, expertise and the global agri-food system - were brought together with genomics.

At first glance, though, this is an association that seems to make little difference to the logics of animal production. The development of genomics-based approaches to breeding for improved productivity and disease resistance does nothing to alter the fact that farmed animals are being bred, as they always have been, for improved efficiency and utility. The introduction of quantitative genetics and now genomics into animal breeding has simply improved the detail and efficiency of the breeding process. Certainly some of the issues for social scientists around genomics identified 
by Michael Banner and Jonathan Suk $^{5}$ are present. Current concerns around genomics and globalisation, governance and regulation, and future concerns about the role of social science in genomics policy and interdisciplinary work, could all find illuminating case studies within farm animal genomics. But what do these tell us about farming, about animal production, rather than genomics? Banner and Suk also highlight that social scientists should be concerned about the meaning of genomics for human identity. ${ }^{6}$ But humans are not the only (or even the most numerous) animals encountered by genomics, and surely social scientists should also (if not more so) be concerned about the meaning and consequences of genomics for the identity or form of 'the social' or 'society'. In this paper I tackle what that shift in perspective might entail and take a case study which does tell us something about animal production and about its shifting form.

My starting position is that the question of how to respond to the continual innovation of science and technology is a question of the contemporary and so must be a question for social scientists. The emergence and continual development of genomics and its associated fields is a contemporary phenomenon in the usually understood sense, in that it is novel and current, and this raises social issues as discussed by Banner and Suk. But the contemporary takes on other connotations when we try to pin down exactly what is contemporary about a given situation. Take the example of a new model of car. ${ }^{7}$ Car design has changed over many years, but the various technologies and components of a car can be dated to different periods in the past. What is contemporary about a new car is its overall design, the way in which its components are currently assembled together and packaged. For anthropologist Paul Rabinow, the social question of the contemporary is all about the form that various interconnected elements take at any given point in time - literally about the shape of events. ${ }^{8}$ In a similar vein, Nick Bingham has outlined a way of thinking that might "stop us from fetishising or becoming fixated on the objects, techniques, and processes of our newest scientific "revolution". 9 "He suggests that we ask "what do particular biotechnologies materialise next to, in the neighbourhood of, connected with, and so and so on and so forth?". 10

Following Bingham's logic, the position of genomics in the hinterland of my research becomes something of a virtue. By examining a genomics-based technology as only part of a set of contemporary connections - in this case of animal disease and food risk - I illuminate the potential scope of the 'social aspects' of animal genomics. In order to do this, in the following section I outline a particular understanding of 'the social' and then present a cognate account of invention that provides us with the key concept of the 'informational material environment'. The next section goes on to outline the informational material environment of TraceBack, a technology for meat traceability.

\section{Socialising and inventing}

Whilst nonhuman animals have always figured in human culture, ${ }^{11}$ they have had little direct presence in sociological concerns. ${ }^{12}$ In recent years a number of researchers, in geography in particular, have sought to address this lacuna. ${ }^{13}$ The position I start from here is that it is not enough to simply acknowledge animals as

Genomics, Society and Policy, Vol.3, No.2 (2007) ISSN: 1746-5354

(C) ESRC Genomics Network. 
sociological actors within a conventional view of society. Rather, it is better to rethink our idea of society or the social in such a way that the inclusion of nonhuman animals (or any other nonhuman thing for that matter) becomes obvious. The particular saliency of the concepts of 'socialising' and 'invention' that I am going to outline can be traced in part to the philosophy of Alfred North Whitehead. With his focus on reality as process, Whitehead used the term society in a way rather different to the now conventional sociological understanding. For Whitehead, a society, rather than being a bundle of 'social relationships' between people, was any composite entity (whether it involved humans or not) that endured over time. ${ }^{14}$ To describe something as 'social' designates only that there is something interesting about the way that it is assembled and held together over time and space, whilst saying nothing about what it is, or how it is held together. ${ }^{15}$ These ideas resonate strongly with the spatial and temporal understandings of form, interconnection and association that Rabinow and Bingham espouse.

Practitioners of Science Studies, particularly those now associated with ActorNetwork Theory (ANT), have explored such ideas though studies of laboratories and technological development processes. They have arrived at a view contrary to the usual sociological position that society can be introduced as an explanatory factor, suggesting instead that society itself is always what requires explanation. This position has been termed a 'performative' view of society. ${ }^{16}$ What this means is that society is not a permanent, solid backdrop to actions. Instead, society is that which those actions continually produce. Which begs the question: what constitutes those productive activities? They are variously constituted through different "modes of existence" ${ }^{17}$ such as religion, law, family, the state, commerce, the sciences etc. - all of those things which we assign to the domain of the 'social' as long as we think society is behind them, structuring them. Society is made up from all of those types of activity which provide us with ways to talk about, experience and order the world, activities which make reference to an outside world and which provide some commonality, however fleeting. The conventional view of society could be termed 'extensive' (society is all-encompassing and exists outside of action) and the performative view 'intensive' (society is situated and created through action).

Perhaps because the originators of ANT explicitly examined the intensive practices the actual doing - of science and technology, rather than just the purported philosophies or outcomes, they also took note of the importance of nonhuman things in the continual creation and maintenance of society. All the description, measurement and standardisation of the world and the performance of identity would not endure collectively if it were not for the material technologies that are more durable than face-to-face human interaction. Some of these technologies also permit more diverse forms of interaction with the other nonhuman things that make up the biophysical world. Paralleling Whitehead's usage, the performative view of society is also a view of society as 'more-than-human'. ${ }^{18}$

From this perspective, what do the natural sciences bring to more-than-human society? They are among the ways in which nonhumans are 'socialised'. ${ }^{19}$ This literally means that the sciences make nonhumans amenable to being part of the morethan-human society, part of the ever-changing collection of negotiated associations 
that bind together entities. New members of society (which we often think of as the discoveries of science) are identified, classified, measured, formatted, understood and made available to existing members of society through those understandings. ${ }^{20}$ So the sciences that make nonhuman animals their object are a way in which nonhuman animals are socialised - although they are far from the only way, as nonhuman animals have clearly been part of more-than-human societies for a very long time. A performative understanding of this process suggests that socialising is not merely a process of bringing things that are 'out there' 'in here'. Rather than the discovery of already existing objects in the world, the sciences are engaged in invention. ${ }^{21}$ And rarely, in the age of molecular biology and particle physics, are the nonhuman objects of the natural sciences as readily identifiable by the layperson as a whole animal. A social conceptualisation of invention, as I will outline it here, can also tell us more about the nature of nonhuman entities as they are socialised.

Invention is an essential element of the sciences' capacity to socialise and is also the key to their capacity to drive technological innovation. As Whitehead stated with regard to the increased professionalisation and institutionalisation of scientific research: "the greatest invention of the $19^{\text {th }}$ century was the invention of the method of invention". ${ }^{22}$ In outlining some important features of invention in science-driven pharmaceutical development, Andrew Barry ${ }^{23}$ draws on the work of both contemporary philosopher Isabelle Stengers (herself influenced by Whitehead) and $19^{\text {th }}$ Century sociologist Gabriel Tarde ${ }^{24}$ to give a performative view of invention. Tarde conceptualised interaction amongst humans in terms of imitation and invention. Imitation is the process by which ideas, practices, technologies and so on spread, whilst invention is the creation of new configurations of elements, new composite entities which will go on to be part of ever more complex composites. In a manner analogous to Whitehead's societies and the notion of the contemporary outlined in the introduction to this paper, these new composite entities are not simply reducible to their original elements.

Such a notion of invention infuses the work of Stengers on modern science, as she focuses on the invention of questions, new composites and the experiments that put them to the test. ${ }^{25}$ In his analysis of pharmaceutical R\&D, Barry makes use of a history of chemistry written by Stengers and Bensaude-Vincente. ${ }^{26}$ He takes the term "informed materials" to describe more specifically what is invented in pharmaceutical $\mathrm{R} \& \mathrm{D}$ processes if Tarde's sociological perspective is adopted. The composite nature of the invented molecule is evidenced in its "informational material environment" the accumulated data on the molecule and its action, the legal information about intellectual property rights, computer models and databases and so on. ${ }^{27}$ The perception and comprehension of the invented molecule are inseparable from this informational material environment. ${ }^{28}$

These insights add extra potency to Bingham's suggestion that we examine what new biotechnologies materialise with. The process of invention results in more than just a novel object, technique or process. It produces complex composites, informed materials inseparable from their informational material environment. Informational material environments are a way of conceptualising the socialised form of an object. They are shorthand for the many practices of observation, measurement, recording 
and production that are necessary to make an object mobile and interactive. In the informational material realm of genomics, the molecules of genes themselves literally encode information about their potential interactions and the further informational material environment such interactions will generate. And it has become increasingly apparent that this information is embedded in the wider material interactions of genome, proteome and other biological systems. The problem we have now is that, with such complex composites, it becomes difficult to isolate exactly what is being socialised/invented - introduced in a novel way - and what the ramifications may be within contemporary events. The next section of the paper examines a specific invention and aims to place it within its informational material environment.

\section{Risk and traceability}

Identigen's DNA TraceBack ${ }^{\mathrm{TM}}$ technology makes use of key elements of contemporary genetic/genomic science: single nucleotide polymorphisms (SNPs consistently located small variations in the genome of a species) an ultra-high throughput genotyping platform and integrated information technology interfaces. ${ }^{29}$ Identigen was founded in 1996 by researchers from Trinity College Dublin's Institute of Genetics with the intention of providing guaranteed traceability of beef products through genotyping. The Irish supermarket Superquinn participated in the technology proving and became the first supermarket chain in the world to guarantee the traceability of its beef through the use of TraceBack "to identify not only the farm the animal has come from, but the actual animal of origin as well" ${ }^{30}$ and to present this information to customers in its product labelling. SuperQuinn claimed an $11 \%$ increase in beef sales from 1999 to 2000 , following the introduction of TraceBack. ${ }^{31}$ In 2001 Superquinn won the Unilever Award from the International Grocery Distributors in recognition of its use of TraceBack in response to customer needs ${ }^{32}$. The success of TraceBack continued when, in 2006, Tesco announced that it would also use the technology for beef traceability in its Irish operation. Taken by itself this story of an innovative biotechnology raises questions. Why do supermarkets need to be able to trace their beef products? Why is this a customer need? What are the circumstances that led to the invention of TraceBack? These all concern animal diseases.

We need to take a small diversion. Much of my research has focused on the development of discourses and technologies of biosecurity in agriculture, during and after the 2001 FMD epidemic. More complete stories about biosecurity can be found elsewhere ${ }^{33}$ for the purposes of this paper it is necessary only to note the analytical direction it points us in with respect to animal diseases. In relation to agriculture, biosecurity is usually taken to refer to the environmental elements of disease prevention and control, a range of hygiene procedures and management techniques that can maintain a separation between crops or livestock and pathogens. In the UK, biosecurity used to be confined largely to technical discussions and was not widely used amongst farmers. During the 2001 FMD epidemic, biosecurity became a watchword for disease control policy, a discourse to shift responsibility for the epidemic and its mismanagement from government to farmers, and a reason for the surveillant control of people. ${ }^{34}$ In wider scientific circles, it is acknowledged that biosecurity entails more than just on-farm hygiene; it "involves all sorts of things like

Genomics, Society and Policy, Vol.3, No.2 (2007) ISSN: 1746-5354

(C) ESRC Genomics Network. 
the testing of animals, the vaccination of animals, isolation facilities, and so on."35 And, to further muddy the waters, outside of mainstream political and agri-food industry understandings of biosecurity, preliminary findings in some recent research have suggested that we should also conceive of biosecurity as involving both animal welfare and the health and safety of consumers with respect to disease in the food chain. ${ }^{36}$ Adding yet another dimension, Bruce Braun has characterised biosecurity as a geopolitical strategy that seeks to deal with the unpredictability of the biological world. He defines this unpredictability in terms of the 'virtuality' or continual emergence that marks biological systems and situates the debate in terms of the 'molecularization of life', emphasising the collective plunge into uncertainty and insecurity that has resulted from "advances in molecular biology, genetics and biochemistry" and the view of the world they provide. ${ }^{37}$

In short: the increased discursive focus given to biosecurity marks an increased attention to biological risk ${ }^{38}$ in various forms. The rise of biosecurity discourse in UK agriculture is not primarily about disease management, but about risk management and about the new forms that this might necessitate. ${ }^{39}$ And risk has received a lot of attention from social scientists in recent years. For instance, in 1999, Sheila Jasanoff gave an overview of two decades of research and noted that risk had "become the organising concept that gives meaning and direction to environmental regulation" 40 (italics in original). More recently it has been noted that standardised methods of risk assessment and risk management have become major drivers in every sphere and level of public and private sector decision-making. ${ }^{41}$ Risk thinking is a key component of all contemporary modes of organisation and regulation, and social scientists have, throughout the rise of modes of risk thinking and risk-based regulation, attempted to demonstrate that risk denotes more than just the probability of something bad happening. ${ }^{42}$ Jasanoff sums this work up as demonstrating that risk is "the embodiment of deeply held cultural values and beliefs ... concerning such issues as agency, causation and uncertainty." 43

Although risk is not a new way of thinking or ordering, ${ }^{44}$ many commentators note that new categories of risks are emerging, especially with respect to food and agricultural production. ${ }^{45}$ It has become common for social scientists to assert, following Ulrich Beck, ${ }^{46}$ that we now live in a 'risk society'. Wealth production, through technological development, has led to the production of new risks. Using risk in this sense denotes the production of material circumstances that could have potentially widespread detrimental effects on the environment and human beings. As they evidence in food scares, these new types of risk follow more complex pathways, further distanciated in time and space and less visible to a consuming public. ${ }^{47}$ All of which highlight the importance of Jasanoff's observation about the contingent construction or 'embodiment' of risk.

Another way to think about these modernisation risks, following an ANT approach, is in terms of an increased 'entanglement' in the world. ${ }^{48}$ In terms of the conceptual framework outlined in the previous section this would consist of a multiplication of new social composites through technoscientific invention. From a similar conceptual starting point Stassart and Whatmore ${ }^{49}$ have argued that these types of food risk are 'transacted' as a property of both the growing distance between producer and 
consumer - both physically and in terms of knowledge and practices - and the enduring physical/bodily and emotional closeness that people have to food. Such is the strength of these connections that even animal disease episodes that do not pose great risks to human health (such as FMD) can have an impact on consumer confidence as they demonstrate the vulnerabilities of complex agri-food systems. ${ }^{50}$

One of the key animal disease/food scare episodes of recent years determined the informational material environment - the set of entangled relationships of production technologies and consumption practices - which gave rise to TraceBack. The crisis surrounding Bovine Spongiform Encephalopathy (BSE) has been held up as having the same impact on agriculture as Beck's favourite example of a modernization risk, radiation as epitomised by the Chernobyl disaster, did on the nuclear power industry. ${ }^{51}$ The story of BSE is now widely known and researched, but I will rehearse the key elements here.

BSE is caused by an abnormal form of a prion protein found in the nervous system of cattle. It was first identified in cattle in England in 1986, but it is thought that the disease may have developed, unclassified, during the 1970s. ${ }^{52}$ The rapid spread of the disease amongst cattle in the late 1980s was attributed to the widespread use of cattle feed containing meat and bone meal (MBM) from rendered carcasses, which in turn could contain remnants of brain and spinal tissues of BSE infected cattle. The use of MBM had been seen as a symbol of modern efficiency within agriculture. It recycled more easily metabolised animal protein, of which there was surplus production, and led to a reduction in dependency on US soya producers for animal feed. ${ }^{53}$

Nevertheless, the emergence of BSE led to a ban in the use of MBM (though this was by no means a straightforward process ${ }^{54}$ ). Worse was to come though when, in 1996, a link was announced between BSE and a new variant of a human disease, Creutzfeldt-Jakob Disease (vCJD). This turned what had been a big problem for the beef industry into a public food scare. BSE came to epitomise the view of industrialised, intensive agriculture as a source of risk and harm that had been building through controversies about water pollution and concerns over animal welfare and widespread biodiversity and habitat loss.

The crisis in the UK involved controversial science over the nature and transmissibility of the disease and failings amongst policymakers to fully take into account the uncertainty of the science. ${ }^{55}$ Across Europe BSE, as it spread to the beef herds of other countries, threw food safety politics into disarray. ${ }^{56}$ In fact, Knowles et al. ${ }^{57}$ note BSE as a key factor in shifting the food safety policy of the EU from a product-based approach to a consumer-orientated one. BSE had huge economic impacts on the beef sector, both as a result of import bans from BSE free countries and a loss of consumer confidence. In an attempt to combat the latter component of the risk 'transacted' by BSE, the EU Council of Ministers introduced a requirement for cattle registration and the labelling of beef to indicate its origins. ${ }^{58}$ There was debate within the European parliament as to whether this be classed as a market measure (to restore consumer confidence and improves sales) or as a consumer safety measure. Ultimately it was classed as both, with the aim of creating an "uninterrupted chain" between producer and consumer. ${ }^{59}$ According to the website of the European 
Commission's Directorate General Agriculture "these rules enable full traceability of cattle, and the meat they produce, from stable-to-table". ${ }^{60}$

At this point, TraceBack re-enters the story. DNA identification for pedigree breeding is a well-established feature of livestock production, providing a basis for the extension of genetic identification techniques into animal and meat traceability. ${ }^{61}$ So the conceptual and material basis for TraceBack existed when Ciaran Meghen was conducting his doctoral research into the molecular genetic relationships between cattle breeds at Trinity College Dublin. ${ }^{62}$ When the BSE crisis emerged, Meghen turned his research towards commercial application and co-founded Identigen to develop the technology that would become TraceBack. As Meghen noted, during the BSE crisis "most commentators were suggesting that traceability was a major issue. That's what inspired the idea". ${ }^{63}$ EU regulations around labelling and the emergence of similar requirements for demonstrating the provenance of beef by other beef importing countries have ensured a ready market for Identigen's product. ${ }^{64}$

Does the invention of TraceBack entail only the technical sampling and testing processes? The social conceptualisation of invention outlined above would suggest there is more in play. ${ }^{65}$ A pointer to what else is part of the informational material environment of TraceBack lies in the very issue that gives rise to the need for genetic traceability: "Conventional animal identity is lost once the carcass is divided up". 66 Once an animal is slaughtered and the carcass butchered it becomes next to impossible to retain traceability of its various products through the industrialised food chain using conventional labelling techniques. However, the animal's genotype remains a constant identifier; it can be extracted from the whole live animal, the carcass or the various parts of the divided carcass. First, the animal or carcass is sampled. Identigen has specific proprietary sampling tools for use in either abattoirs or when an animal is tagged (ear tagging is another requirement of the EU regulation). Then the genetic profile is stored centrally and TraceBack's rapid genotyping permits a reconstruction of the animal's unique genetic identity, and hence its origin and point of entry to the food chain, from any part of its body. Although the materiality of the animal body is not literally invented by TraceBack, part of the invention of the technology is certainly the translation of animal bodies into informed materials. In doing this, TraceBack re-invents animal identity into a more manageable format. The informed materials of the animal bodies themselves join the sampling, genotyping and data handling devices as part of the TraceBack technology. But the informational material environment of TraceBack extends still further.

Using TraceBack, any animal disease or other food risk incident could be quickly traced to source. But, as noted previously, the introduction of labelling and traceability are not only (perhaps not even primarily) concerned with the materiality of consumer safety. Although we have now arrived at a situation where the meat supply chain is driven by the consumer demand for safe food, it is not enough to simply produce safe and wholesome food. The production process must be communicated to consumers, prompting a range of methods of providing consumers with information about their food products. ${ }^{67}$ Quality assurance schemes and their associated labels communicate to consumers that their meat has been produced under certain standards of animal health and welfare or consumer safety. As well as being a 
signifier of provenance in itself, the guaranteed traceability that Identigen promotes TraceBack as offering also provides a reliable means for supermarkets to audit the quality assurance schemes they have in place along their supply chains, crosschecking their suppliers and ensuring their ability to back up their claims to consumers. TraceBack's brand can be added to food labels alongside the retailers own quality branding. Some research, however, suggests that quality assurance labelling has little impact on consumer perceptions, relegating such schemes to little more than production-focussed modes of supply chain management. ${ }^{68}$ As a final note here, TraceBack itself is a product with a rich environment of marketing information. It is this element of the informational environment which makes TraceBack's 'offer' to retailers.

Ultimately, TraceBack's informational material environment, from which it is inseparable, extends backward and forward in time from the moment of its invention. Its action is informed by not only the science that has gone before, but also by the relations of risk in which it intervenes. Its invention is also informed by the claims it will permit its users to make about the safety and traceability of their food as it shift the ways in which risk is transacted. Yet for all this, TraceBack is only as innovative a solution as the forward elements of its complex environment (in this case the consumers being communicated with) enable it to be by their response.

\section{Concluding Remarks}

Braun sees our current focus on biological risk (under the auspices of biosecurity) as a political response to the increasingly prominent vision of life on a molecular scale and the relative unpredictability that being immersed in such a molecular world seems to heighten. This observation, whilst true on a particular scale, presents the science that leads to a molecularization of life and the politics that result from it as distinct and related in a linear fashion: "biosecurity today names a set of political responses",69 (emphasis added). Others have argued that, rather than a progressive molecularization of life, we are now witnessing the "re-biologization" of life. ${ }^{70}$ This re-biologization is encapsulated in the current experimental and exploratory efforts to obtain biologically useful information from the massive amount of genomic data collected. ${ }^{71}$ The application of systemic approaches from genome mapping through to functional genomics and so on, generates informational material environments that incorporate the social and political elements of dealing with risk, the entanglement of heterogeneous materials (including re-invented animal bodies) and the raising of difficult choices. In the practice of contemporary biology and its application in biotechnologies, politics and science are inextricably linked at a material level.

TraceBack exemplifies this situation as it contributes to the socialisation of disease risk in novel ways. It is an invented technology that is nothing without the already existing animal body, which it then in turn re-invents in the light of an inseparable genotypic identity. Yet TraceBack also could not exist in the form it takes without the complex social composite (of regulation, politics and risk) engendered by BSE. Moreover, TraceBack's interaction with risk is not simply on a molecular level. It is part of a wider informational material environment in which animal identity might have been rendered temporarily more stable, but in which consumer behaviour does

Genomics, Society and Policy, Vol.3, No.2 (2007) ISSN: 1746-5354

(C) ESRC Genomics Network. 
not have to comply. A focus on genomics alone cannot bring out these types of interactions. It is through the juxtaposition of risk and TraceBack - comparable only as social forms in the abstract - that they become apparent in this case. Bingham asserts that insights about the living world can be best gained "from the muddle of the middle", ${ }^{72}$ where our ideas of nature and society (or indeed science, technology and politics) do not come apart easily. This brings us to what we might mean by the social dimensions of animal genomics.

I would suggest that we need to get away from thinking about social questions or issues as being those that belong in some hazily visualised domain designated 'the social'. The various related ideas of collectivity put forward here - the contemporary, the enduring composite, the performative view of society, invention as the production of complex composites and informed materials - all present a view of 'the social' as nothing more than a description of interaction, of more-or-less enduring associations. None of them offers any explanation; they exist only as methodological aids to focus the attention and assist in the description of the world. They implicitly reject the totalising, explanatory character of such earlier concepts as 'culture' and 'society', concepts that many feel no longer have any purchase in our entangled and always shifting contemporary moment. ${ }^{73}$ Social issues are something all together broader in definition: they are all of those concerns generated through the production and interaction of new composite entities. If we want to have a social science that is attentive to nonhuman as well as human animals, that can say something novel and useful about animal genomics, then we have to have a social science that is also attentive to molecules, genomes and the whole array of technical and scientific objects, techniques and tools that constitute informational material environments. I have attempted to illustrate and adopt just such a perspective in this paper. Extending it further leads me to two more general conclusions that remain pertinent to studying genomics.

A focus on the inseparability of objects, their informational material environments and their perception by others leads to an interesting set of concerns. The categories of farmed animals, wild animals and companion animals differ from each other in ways that have less to do with easily made distinctions such as 'domestication' and 'food production' and more to do with the many and varied informational material environments that those processes create. Farmed animals in particular are informed materials, embodying varying degrees of information and inhabiting more-or-less complex informational environments depending on the levels of research and intervention that have gone into their development. The new ways of seeing and understanding raised by genomics both highlight this feature of their existence and extend its potential complexity and richness.

Putting concepts together in the ways that I have done could be seen as an endless set of word games. However, it can also serve a useful function. Borrowing from Isabelle Stengers ${ }^{74}$ I would term this process the invention of problems. Problems are not a given, they are brought into play through many and varied interactions ${ }^{75}$ and it is the job of the scientist (social or otherwise) to actively engage in their framing and invention. This active perception of invention and intervention can lead us to make problems that are more inclusive in their articulation, ${ }^{76}$ an issue of particular saliency 
when considering the relative paucity of studies that fully engage with more-thanhuman society.

\footnotetext{
${ }^{1}$ Centre for Rural Economy, Newcastle University andrew.donaldson@ncl.ac.uk

${ }^{2}$ I follow the BBSRC in its definition: "we use the term Farm Animal Genomics to encompass a range of genomics and genetics approaches it is defined as: 'Science that promotes the understanding of genetics and gene function in livestock animals and the application of this knowledge to life sciences in general, in particular to farm animal health and welfare, product quality and efficiency, and human health'." (BBSRC. 2005. Review of Farm Animal Genomics in relation to BBSRC-Funded Research: 4).
}

${ }^{3}$ The eventual cost of the epidemic would be in the region of $£ 8$ billion, with greater losses occurring in tourism and other sectors outside of agriculture that had not become apparent at the time of the documentary. See A. Donaldson, R.P. Lee, N. Ward \& K. Wilkinson. 2006. Foot and Mouth - Five Years On: The Legacy of the 2001 Foot and Mouth Disease Crisis for Farming and the British Countryside. Centre for Rural Economy Discussion Paper 6.

${ }^{4}$ This sense of import is echoed by the BBSRC, op. cit. note 2, p.31.

${ }^{5}$ M. Banner \& J.E. Suk. Genomics in the UK: Mapping the Social Science Landscape. Genomics, Society and Politics 2006; 2:1-27.

${ }^{6}$ Ibid, p.23.

${ }^{7}$ This exposition of 'the contemporary' originates with Michel Serres in M. Serres \& B. Latour. 1995. Conversations on science and technology. Michigan. University of Michigan Press.

${ }^{8}$ See P. Rabinow. 1999. French DNA. Chicago. University of Chicago Press; P. Rabinow 2003. Anthropos Today: Reflections on Modern Equipment. Princeton. Princeton University Press.

${ }^{9}$ N. Bingham. Bees, butterflies and bacteria: biotechnology and the politics of nonhuman friendship. Environment and Planning A 2006; 38: 483-498.

${ }^{10}$ Ibid.

${ }^{11}$ For a recent overview see L. Kalof \& A. Fitzgerald. Eds. 2007. The Animals Reader. Oxford. Berg.

${ }^{12} \mathrm{H}$. Tovey. Theorising nature and society in sociology: The invisibility of animals. Sociologia Ruralis 2003; 43: 196-214.

${ }^{13}$ Eg, C. Philo \& C. Wilbert. Eds. 2000. Animal Spaces, Beastly Places: New Geographies of Humananimal Relations. London. Routledge.

${ }^{14}$ See A.N. Whitehead. 1929. Process and Reality. Corrected Edition. Macmillan USA [1979].

${ }^{15}$ B. Latour. 2005. Re-assembling the Social. Oxford. Oxford University Press.

${ }^{16}$ B. Latour. The Powers of Association. In J. Law (Ed). 1986. Power, Action and Belief: a new Sociology of Knowledge? London, Routledge and Kegan Paul. For recent accounts of Science Studies' lessons for sociology in general see Latour, op. cit. note 15; J. Law. 2004. After Method: Mess in Social Science Research. London. Routledge.

${ }^{17}$ B. Latour. A Plea for Earthly Sciences. Presented to the Annual Meeting of the British Sociological Association. East London. 2007.

${ }^{18}$ The phrase as used here belongs Sarah Whatmore, eg, S. Whatmore. Materialist returns: practising cultural geography in and for a more-than-human world. Cultural Geographies 2006; 13: 600-609.

${ }^{19}$ See B. Latour. 2003. The Politics of Nature. London. Harvard University Press. In a similar vein, the social sciences are a way in which humans are socialised. For a commentary on the performativity of the social sciences in the modern state and their role in the constitution of the society they purport only to describe, see J. Law \& J. Urry. Enacting the Social. Economy and Society 2004; 33: 390-410.

${ }^{20}$ The classic ANT examples of the socialisation of nonhuman entities are Latour's account of Pastuer and his microbes and Callon's Scallops in St Brieuc Bay (see B. Latour. 1988. The Pasteurization of France. Cambridge, Massachusetts. Harvard University Press; M. Callon. Some elements of a sociology of translation: Domestication of the scallops and the fishermen of Saint Brieuc Bay. In Power, Action and Belief: a new Sociology of Knowledge? J. Law, ed. London. Routledge and Kegan Paul: 196-233.) Steve Hinchliffe provides an excellent account of the fractured and resisted attempts to isolate, and make amenable to political intervention, a causal agent for BSE (S. Hinchliffe. Indeterminacy in-decisions: science, policy and politics in the BSE crisis. Transactions of the Institute of British Geographers 2002; 26: 182-204). 
${ }^{21}$ This point, variously expressed, is central to an ANT approach. In this paper it will have to take the status of an axiom, but for further discussion see J. Law. op. cit note 16; I. Stengers. 1997. The Invention of Modern Science. Minneapolis. University of Minnesota Press.

${ }^{22}$ A.N. Whitehead. 1925. Science and the Modern World. New York. Free Press [1967].

${ }^{23}$ A. Barry. Pharmaceutical Matters: The Invention of Informed Materials. Theory, Culture and Society 2005; 22: 51-69.

${ }^{24}$ Tarde's work has also been repeatedly cited by Bruno Latour as a forgotten precursor to ANT.

${ }^{25}$ Stengers 1997, op. cit. note 21; I. Stengers. 2002. Power and Invention. Minneapolis. University of Minnesota Press.

${ }^{26}$ A. Bensaude-Vincente \& I. Stengers. 1996. A History of Chemistry. Cambridge, Massachusetts. Harvard University Press.

${ }^{27}$ Barry, op. cit. note 23, p.59.

${ }^{28}$ For more on this view of perception see A.N. Whitehead. 1920. The Concept of Nature. Cambridge. Cambridge University Press.

${ }^{29}$ See http://www.identigen.com/dna brand.php

${ }^{30} \mathrm{http}: / /$ www.superquinn.com/Multi/default.asp? $\mathrm{id}=301$ \&itemId=301\&Section=Nutrition\%20Forum

${ }^{31}$ Identigen press release March $14^{\text {th }} 2001$.

${ }^{32}$ Identigen press release October $12^{\text {th }} 2001$.

${ }^{33}$ A. Donaldson. Biosecurity after the event: Risk politics and animal disease. Forthcoming in Environment and Planning A; A. Donaldson \& D. Wood. Surveilling strange materialities: categorisation in the evolving geographies of FMD biosecurity. Environment and Planning D: Society and Space 2004; 22:373-391; B. Braun. Biopolitics and the molecularization of life. Cultural Geographies 2007; 14:6-28.

${ }^{34}$ Donaldson \& Wood, op. cit. note 33.

${ }^{35}$ D. Black, Select Committee on Environment, Food and Rural Affairs. Minutes of Evidence, October 16, 2002.

${ }^{36}$ E. Roe and A. Evans. Animal Welfare: A form of bio-security? Paper presented to the Annual Meeting of the Association of American Geographers in Chicago 2006.

${ }^{37}$ Braun, op. cit. note 33, p.6. Braun's argument is essentially about offering an alternative view on the political outcomes of the molecularization of life to that put forward by Nikolas Rose (N. Rose. The politics of life itself. Theory, Culture and Society 2001; 18: 1-30).

${ }^{38}$ A. Donaldson. Biosecurity and the re-ordering of risk. Presented to the Annual Meeting of the Association of American Geographers. Chicago 2006. Donaldson, op. cit. note 33; Braun, op. cit. note 33.

${ }^{39}$ The Department for Environment, Food and Rural Affairs has a number of public/private partnership groups working on the best ways to facilitate improvements in animal health and farm management for both industry and public benefit.

${ }^{40}$ S. Jasanoff. The Songlines of Risk. Environmental Values 1999; 8: 135-152.

${ }^{41}$ M. Power. 2004. The Risk Management of Everything. London. Demos. H. Rothstein, M. Huber \&

G. Gaskell. A theory of risk colonization: the spiralling regulatory logics of societal and institutional risk. Economy and Society 2006; 35: 91-112.

${ }^{42}$ See, for example, S. Lash, B. Szerszynski and B. Wynne. Risk, Environment and Modernity. London. Sage.

${ }^{43}$ Jasanoff., op. cit. note 40, p.135.

${ }^{44}$ P. O’Malley. Introduction: configurations of risk. Economy and Society 2000; 29: 457-459.

${ }^{45}$ A.P.J. Mol and H. Bulkley. Food Risks and the Environment: Changing Perspectives in a Changing Social Order. Journal of Environmental Policy \& Planning 2002; 4: 185-195.

${ }^{46}$ U. Beck. 1992. Risk Society. London. Sage.

${ }^{47}$ Mol \& Bulkley op.cit. note 45.

${ }^{48} \mathrm{~B}$. Latour. Is re-modernization occurring - and if so, how to prove it? Theory, Culture and Society 2003; 20: 35-48.

${ }^{49}$ P. Stassart and S.J. Whatmore. Metabolising risk: food scares and the un/re-making of Belgian beef. Environment and Planning A 2003; 35: 449-462.

${ }^{50}$ E.P. Cunningham. 2003. After BSE - A future for the European livestock sector. European Association for Animal Production, scientific series, vol. 108. 
${ }^{51}$ P. Oosterveer. Reinventing Risk Politics: Reflexive Modernity and the European BSE Crisis. Journal of Environmental Policy \& Planning 2002; 4: 215 - 229.

${ }^{52}$ The BSE Inquiry. Volume 1: Findings and Conclusions. London. The Stationary Office.

${ }^{53}$ Oosterveer, op. cit. note 51.

${ }^{54}$ See Hinchliffe, op. cit. note 20.

${ }^{55}$ Hinchliffe, op. cit. note 20. The BSE Inquiry, op. cit. note 52.

${ }^{56}$ Oosterveer, op. cit. note 51.

${ }^{57}$ T. Knowles, R. Moody \& M.G. McEachern European food scares and their impact on EU food policy. British Food Journal 2007; 109: 43-67.

${ }^{58}$ Initially in 1997 under Council Regulation (EC) 820/97 which was later replaced with Regulation (EC) 1760/2000 Of The European Parliament and of The Council.

${ }^{59}$ Knowles et al. op. cit. note 57.

${ }^{60} \mathrm{http}: / /$ ec.europa.eu/agriculture/foodqual/beef/label en.htm

${ }^{61}$ E.P. Cunningham and C.M. Meghen. Biological identification systems: genetic markers. Scientific and Technical Review of the Office International de Epizooties 2001.

${ }^{62} \mathrm{http}: / /$ www.identigen.com/leadershipteam.php

${ }^{63}$ Moo Tech Fingerprints Mad Cows. Wired Med-Tech Section, November $6^{\text {th }}, 2001$. Available at http://www.wired.com/medtech/health/news/2001/11/48005?currentPage=1.

${ }^{64}$ The poor traceability from slaughterhouse to retail identified by the EU Food and Veterinary Office (FVO Special Report DG(SANCO) 9505/2003) is utilised by Identigen Chairman, Patrick Cunningham - also Chief Scientific Advisor to the Irish Government - to highlight the importance of TraceBack. See P. Cunningham. Food, Livestock, Health - some applications of biotechnology. Paper presented to EU-India Workshop on Biotechnologies. New Delhi 23-24 April 2007.

${ }^{65} \mathrm{We}$ could also look back in the innovation process to note how previous inventions are being imitated in the invention of TraceBack. For example, genome sequencing has identified many SNPs as by-products (see BBSRC, op. cit. note 2), which can then be utilised in new projects and technologies. ${ }^{66}$ Cunningham \& Meghen, op. cit. note 61, p.497

${ }^{67}$ X. Gellynck, W. Verbeke \& B. Vermeire. Pathways to increase consumer trust in meat as a safe and wholesome food. Meat Science 2006; 74:161-171.

${ }^{68}$ Ibid.

${ }^{69}$ Braun, op. cit. note 33, p.15.

${ }^{70}$ P. Rabinow and C. Caduff. Life - After Canguilhem. Theory, Culture and Society 2006; 23: 329 331.

${ }^{71}$ Ibid.; See also M. O’Malley and J. Dupre. Fundamental Issues in Systems Biology. Bioessays 2005; 27: 1270-1276.

${ }^{72}$ Bingham, op. cit. note 9, p.496.

${ }^{73}$ Rabinow 1999, op. cit. note 8. See also Latour 2005, op. cit. note 16; Law 2004, op.cit. note 16.

${ }^{74}$ Op. cit. note 21.

75 See also Rabinow (2003, op. cit. note 8) on Foucault's idea of problematisation as the process by which elements are constituted as objects of thought.

${ }^{76}$ See Law 2004, op. cit. note 21; Latour 2007, op. cit. note 18. 